\title{
Efficient use of resources in the field of energy efficiency through the principles of the circular economy
}

\author{
H.N.Yaryhina, I.V.Ziankova, and R.S. Sati \\ Department of Economics, Polotsk State University,Vitebsk Region, Novopolotsk, Belarus
}

\begin{abstract}
The purpose of this study is to define indicators areas of efficient use of resources in a circular economy, aimed at solving energy and environmental problems, as well as to develop theoretical and practical recommendations for their formation. This study defines the conceptual foundations of the circular economy, defines the methodological approach to energy efficiency in terms of alternative energy sources, and develops a theoretical and practical approach to balancing employment in the labour market in a circular economy. As a result of the conducted research using the principles of the circular economy, the category of efficient use of resources in the field of energy efficiency is defined. The scientific novelty lies in the use of a systematic approach to the study of economic phenomena, which revealed the consideration of the interconnection of all elements, as well as the study of individual economic objects as structural parts. The role of each part in the general functioning of the circular economy and its impact on individual elements are defined. The methodology of the study is revealed using methods of comparison, the concept of systems, and statistical approaches.
\end{abstract}

\section{Introduction}

The energy challenge is one of the greatest challenges humanity is facing today. Rising energy prices and growing dependence on imported energy threaten our security and competitiveness. Key decisions need to be made to reduce emissions and combat climate change.

In the coming years, the entire dependence of the population on oil and natural gas will grow. Some fossil fuels will become more complex and expensive to operate [1].

Therefore, one of the most important recent environmental issues is the energy transition. One solution to help accelerate this transition is the circular economy. The whole world has become acutely aware of the environmental problems, especially global warming, climate change, air pollution, freshwater, sea and ocean waters, loss of ecological diversity, shortage of some natural resources,etc. Environmental problems have affected the whole world, both developing and developed countries; therefore, environmental problems are becoming the main concern of the modern world community. It is important to search for new solutions, alternatives in the field of renewable energy using innovative technologies. 
The conditions for the use of resources, ways to assess the economic efficiency of production attracted the attention of scientists and practitioners at the early stages of the development of economic science. In a market economy, the financial result of business activities directly depends on the degree of return of resources in the form of goods and services produced. However, approaches to the problem changed as the conditions of economic development changed. The classics of economic science (A. Smith, D. Ricardo) investigated the return on capital under the conditions of relative freedom of choice of resources [2] The criterion for the use of resources was their productivity; the possibility of choosing the best of them with their heterogeneity was provided. However, the predecessors of the classical economic school, the physiocrats (F. Quesnay, A. Turgot), while studying the use of natural resources in economic activity, had already begun to focus on the problem of limited resources, their diminishing returns with the expansion of production [3] . Nevertheless, economists of the time were primarily concerned with the possibilities of obtaining the highest profit. The extensive production (attracting additional resources) was considered to be the main type of production.

What is resource efficiency? The concept of "resource efficiency" consists of two components: "resource" and "efficiency". To disclose the content of the concept of "resource efficiency", it is acceptable to define a resource as a factor of production that forms the potential, creates the conditions, and is the initial form for the creation of products, works, and services. We can understand resource efficiency as a combination of objective and subjective factors that reflect the degree of satisfaction from the use of resources. The resource efficiency of an industry is a set of criteria reflecting the nature of the use of resources in a particular area of economic activity - the industry. The characteristic of the resource efficiency of the industry mainly reflects the volumes, quality, and dynamics of the consumption of primary fuel and energy resources [4]. In a recent study, SofieHuysman proposed a structured framework in which measures of resource efficiency can be structured and critically analyzed. The purpose of the study was to provide a correct understanding of the theoretical basis of existing indicators of resource efficiency, as well as to pave the way for further development of indicators [5]:

\section{Problem Statement}

The purpose of this study is to identify the areas of efficient use of resources in a circular economy for solving energy and environmental problems, as well as the development of theoretical and practical recommendations for their formation.

The following tasks are set: 1) define the conceptual foundations of the circular economy; 2) determine the methodological approach to energy efficiency in terms of alternative energy sources; 3) develop a theoretical and practical approach to balancing employment in the labour market in a circular economy.

\section{Description of the current situation}

When considering the tasks, the genesis of economic thought was carried out, the authors took into account the experience and research of foreign and domestic studies.

In contemporary international political discourse, efforts towards sustainable development are mainly based on the 2030 Agenda[6] and the 2015 United Nations Sustainable Development Goals [2]. One of the newest documents presented by the European Commission is the Green Deal[7], which aims to transform the European Union into a just and prosperous society with a modern, resource-efficient, and competitive economy, in which there will be no net greenhouse gas emissions (by 2050) and where 
economic growth is not associated with the use of resources[8]. The Green Deal is aimed at protecting, preserving, and enhancing the natural capital of states, as well as protecting the health and well-being of citizens from risks and impacts associated with the environment. At the same time, the transition must be fair and inclusive[7].

At the present stage, many Belarusian and Russian scientists are studying the issue of a green and circular economy: N. Batova, E. Shershunovich; I. Tochitskaya, N.V. Pakhomova , K.K. Richter, G.B. Malyshkov, P. Sachek, Pister E.I., T.A. Selishcheva, Yatskovskaya E.A.[9,10;11,12]. The works of the following authors deserve special attention: Geissendoerfer, Ellen MacArthur Foundation, Gunther Pauli , Julia L. K. Nußholz, Franco Donati, Henning Wilts [13,14,15,16].

Among Belarusian scientists, one can single out the work of Nadezhda Batova "Circular Economy in Belarus: Barriers to Transition" [9]. The paper compares the results of surveys of business entities regarding barriers hindering the development of a circular economy. The work "Circular economy in action: forms of organisation and best practices" [10] presents the advanced experience of implementation of the circular economy, based on the study of best practices.

Among foreign scientists, one can highlight the work of Julia L. K. Nußholz "Circular Business Models: Defining a Concept and Framing an Emerging Research Field". This study clarifies how to form the field of circular business model research by explaining the basics of the concept in terms of resource efficiency and business model innovation. This study contributes to the theoretical advancement and effective implementation of circular business models.

Due to the deteriorating environmental situation around the world, a relevant concept of a circular economy is attracting more and more attention and is of interest not only in the academic community but also in the political environment. It is a systemic solution aimed at mitigating the negative impact of production and consumption on the environment, especially in the context of reducing greenhouse gas emissions and waste.

The importance of the circular economy model is gaining in importance due to the greater added value of each unit of resources compared to the traditional linear model. The circular economy model is based on many "old" as well as still "new" concepts that aim to minimise the environmental impact of enterprises. However, none of the studies has developed specific (precise) methods, steps, and mechanisms on how to introduce elements of a circular economy in the field of energy efficiency to solve energy problems to create an eco-production sector.

\section{Results of studies}

\section{Conceptual Foundations of a Circular Economy}

The review of the literature showed that in various studies the approaches to the concept of the "circular" economy have many interpretations. It can be concluded that the concept of "circular" economy offers effective business models to ensure more environmentally friendly resource management contributing to the achievement of the goals of sustainable development of the society. 


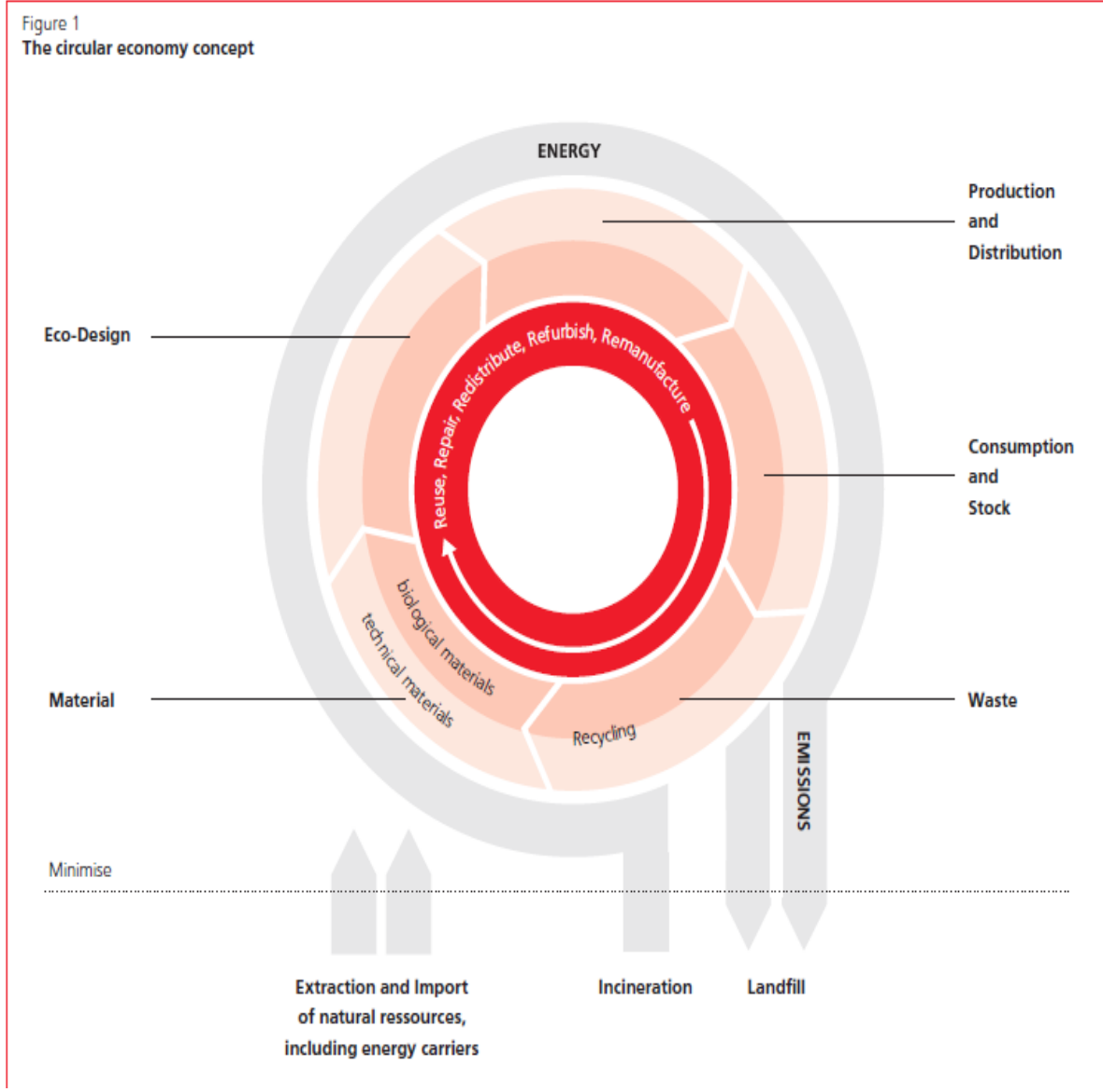

Fig. 1. Holistic concept of circular economy (Source Wiltz, 2016).

The authors believe that the circular economy is a model of an economy in which closed loops are created, alternative to the linear economy, in which resources are in a constant circular motion in the production and consumption system to optimize the use of primary resources and reduce waste at each stage.

The authors rely on the "Blue Economy «theoretical approach by Gunter Pauli. His study describes more than one hundred innovative economic business models that are based on a system of social and environmental benefits from nature. One of the principles of the "blue economy" is to preserve natural resources, replace "something" with "nothing" (a model of unsustainable production) while creating new jobs, increasing the level of competitiveness and business sustainability. This approach solves the following tasks:

1. The problem of environmental pollution, i.e., pollution can be controlled by applying zero-waste technology: reduce, reuse and recycle

2. Transformation into a more efficient and sustainable economy with a focus on social development

3. Conservation of biodiversity and increasing the efficiency of resource management through the use of alternative energy sources and biofuels

4. Creation of new jobs. 
The method of comparison and scientific modeling reveals the role of the circular economy in saving resources, minimizing waste, and reducing pressure on the environment while achieving significant economic and social results. This requires certain steps.

The first step is to change the Belarusian fuel and energy systems by switching from carbon-based energy (oil, gas, coal) to clean energy (solar, wind, hydropower, etc.). But it is also important to follow the principle of energy efficiency, which is to measure the difference between the energy used and the total energy consumed (often higher due to losses) and, accordingly, to reduce consumption. The principle of the circular economy is to achieve the most efficient use of resources. Therefore, it is the key lever for the development of innovative solutions for the transition to clean energy.

The authors propose a conceptual principle of effective resource management in a circular economy for the competitiveness of the region (using the example of the woodworking industry), which is to analyze the efficiency of the use of material resources and the use of production waste. The practical significance of the implementation of the concept lies in the possibility of tracking the chain of rational use of primary raw materials (in the woodworking industry) at all stages of the life cycle, from planning the procurement of raw materials (primary or secondary raw materials), supply, and offending with the processing of products. It is also an opportunity to bring an enterprise to low-waste or non-waste production, the possibility of recycling products produced by this enterprise, along with economic (reduction of negative externalities, and, accordingly, a decrease in the amount of environmental tax) and environmental (reduction of negative externalities, and, accordingly, reduction of environmental damage) benefits.

Circular economy approaches suggest:

- Rational use of natural resources

- Most efficient energy saving (clean energy)

- Recycling of all waste and obtaining new goods, raw materials, and energy (total recycling)

- Renting everything instead of owning (sharing)

- Global automation and digitalization (digital economy).

The circular economy offers:

- Greater resource efficiency

- Greener resource management

- Separation of wealth from resource consumption

- Reuse and recycling involve the use of primary resources

- Improvements of our ability and capacity to meet resource needs.

As an area of expertise, energy efficiency is at the intersection of various disciplines, including technical, legal and social, and economic disciplines. The efficient use of fuel and energy resources is a key element of every country's economy, which has a significant impact on the competitiveness of products, sustainability, stability, and vulnerability of the economy, as well as on the environment. Moreover, improved energy efficiency leads to a stronger national economy. The benefits of energy efficiency are to maximize output per unit of energy, which increases GDP and can provide some other macroeconomic benefits, including job growth, a better balance of trade, lower energy prices, and greater security of supply[17].

The methodological approach to energy efficiency from the point of view of alternative energy sources

Based on the analysis of the study of the concept of "energy efficiency", the authors' vision of this definition and the criterion of "energy efficiency" are as follows:

$\checkmark$ Energy efficiency is the effect achieved by reducing the consumption of fuel and energy resources, taking into account their energy savings over a certain period, aimed at increasing the quality of the resulting product. 
$\checkmark$ The criterion of energy efficiency can be formulated as a category of management, the purpose of which is to achieve an effective result (a certain result) with minimal energy consumption.

The conducted research allowed the authors to state that the concept of circular economy acts as a practical basis for resource efficiency and offers effective business models to ensure more environmentally friendly use of resources, contributing to the sustainable development of society [18] .

The benefits of a circular economy are the following:

- Waste is turned into a resource.

- It is the economy of recovery and reuse.

- It multiplies the productivity of natural resources in terms of resource efficiency.

- It focuses on energy resources.

- It creates green jobs.

-It reduces the amount of resources required for the production of a unit of output thus producing more with less

- It transforms production chains and consumption patterns without linking GDP growth to the use of natural resources.

Energy conservation aims to extract as much energy as possible from its primary sources while conserving the environment and minimizing harm to it. Currently, there is an increasing interest in and competition for serious investments in the development of alternative energy programs and technologies, as well as the introduction and use of green technologies in several areas, which together will determine the world's future energy industry.

Renewable energy is generated from natural sources and is defined as an inexhaustible and rapidly renewable energy source. Renewable energy types are:

- Solar energy that does not pollute the environment and provides significant environmental protection. Reducing greenhouse gas pollution is the main benefit of using solar energy.

- Wind energy

- Geothermal energy as a substitute for fossil fuels significantly reduces $\mathrm{CO}_{2}$ emissions. It is the extraction of heat not only from thermal waters but also from water-bearing rocks using injection of wastewater into strata and converting deep heat into electrical energy which ensures the environmental safety of its production.

- Biomass energy includes the primary wood fuel, secondary wood fuel, peat, waste fuel from industrial and domestic waste, liquid biofuels, non-wood biomass.

- Hydropower, especially small hydropower (water from small rivers) practically does not depend on weather conditions and can provide a stable supply of cheap electricity to the consumer.

The circular economy provides pragmatic and effective solutions for the gradual depletion of vital resources for the functioning of a modern economy. By closing the cycles of materials, water, and energy, this "other" economy allows the economy to grow while reducing extraction from nature [18].

Not all energy efficiency measures are "cost-effective"; investments must be economically viable, taking into account opportunity costs and major fixed and recurring costs. However, simulations for the World Energy Outlook show that harnessing economically viable energy efficiency investments will increase total economic production by $\$ 18$ trillion by 2035 . Macroeconomic models estimate that growth would increase by $0.25-1.1 \%$ per year, with a corresponding increase in employment. Energy efficiency increases output as it frees up resources for other, more productive investments, so the WEO estimates that efficiency measures bring benefits 2.5 times greater than the avoided energy costs. Energy efficiency measures are generally more labor-intensive than 
equivalent investments in fossil fuel supply and create three times more jobs per million dollars of investment[17].

The experience of using alternative energy sources in Lebanon made it possible to observe the following patterns: taking into account regular power outages [Figure 2] throughout the country[19] , a customized project Electricité de Zahlé (EDZ) was created. It operates both in an autonomous mode, with a battery, and in grid-connected mode, when electricity from the EDZ is present and the grid metering is enabled.

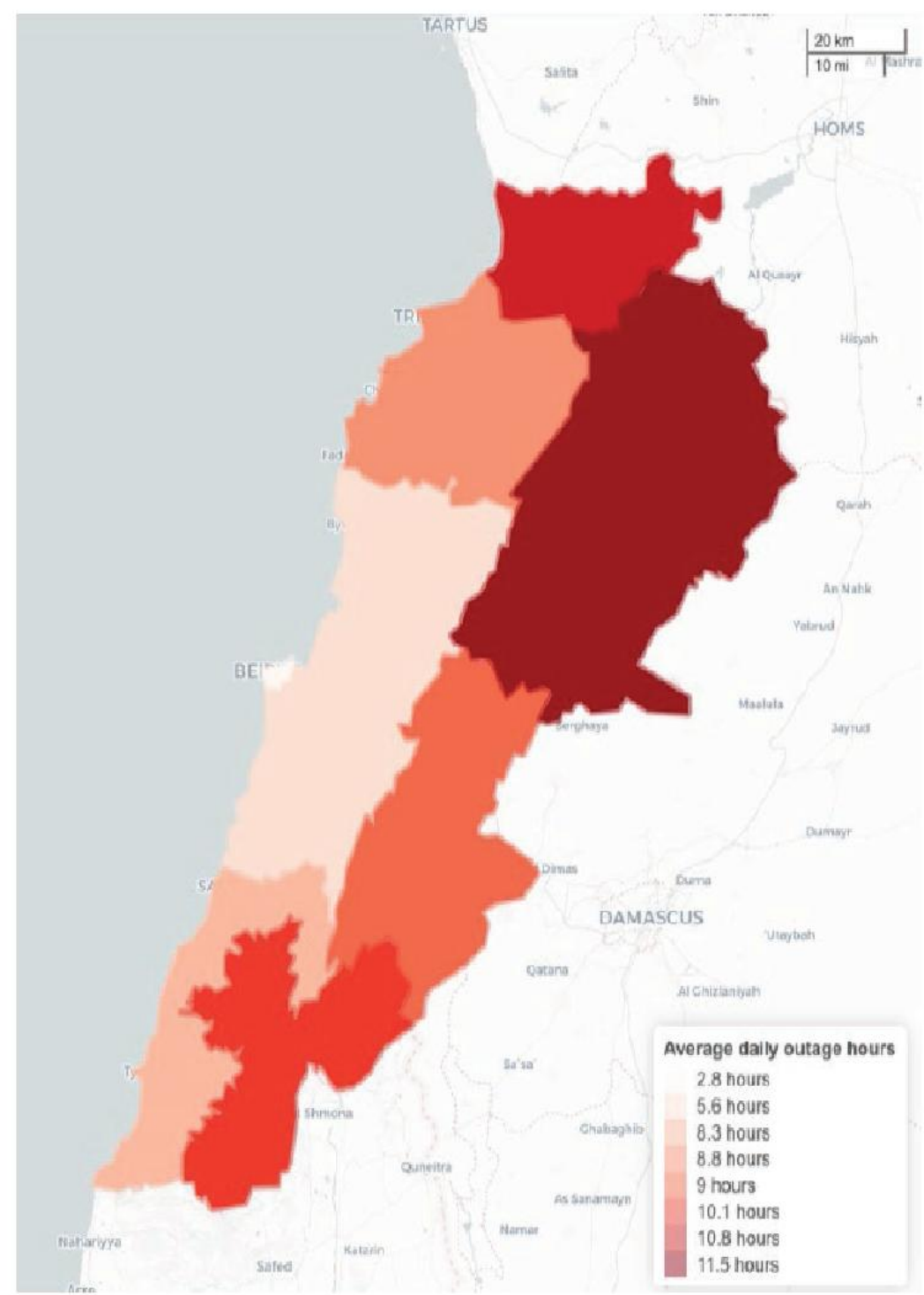

Fig. 2. Regional variation of the average daily outage hours (2018 data; source: EDZ) The gap between the power supplied by the EDZ and demand is covered by expensive, polluting, and noisy diesel generators. 
This means the use of renewable energy sources connected to the grid and providing the load in the event of a grid interruption, synchronized with the water self-generator when the grid is available. It also means that PV and solar energy will power up the grid via a net metering system in case of excess capacity. The project helps to overcome technical and economic barriers and raise awareness of this unique approach so that it can be replicated in the private sector on its own [20].

A theoretical and practical approach to the balance of employment in the labor market in a circular economy

Resource efficiency makes economic sense. It's one of the basic principles underlying the entire circular economy strategy, and it is fundamental to green growth. "Some economists state that policies that do not address environmental issues such as resource depletion, biodiversity loss, floods, and droughts due to climate change can lead to job and livelihood losses. Therefore, addressing environmental issues provides opportunities for workers and employers and reflects economic growth"[18] .

Thus, the authors' vision of the employment category in a circular economy is as follows: the balance of employment in the labor market in a circular economy is a dynamic balance of the professional and qualification structure of labor supply and economically viable jobs to ensure energy efficiency, including through resource conservation, the achievement and maintenance of which is possible taking into account the management of indicators of sustainable economic development that determine the demand and supply of labor resources at each moment of socio-economic, cyclical economic development[21], and the development of a mechanism for the coordination of actions of both parties.

In addition, when testing the model of multiple deterministic factors developed by the authors, the determinants (formula (1)) that determine the nature of changes in the average number of employees ( $\mathrm{P}$, people) employed at the micro-level were revealed:

$$
\mathrm{P}=\frac{\mathrm{LI} \times \mathrm{S}_{\mathrm{p}} \times \mathrm{S} R \times \mathrm{CC} \times \mathrm{PV}}{\mathrm{CL}}
$$

Where LI is the labor intensity of the product, people/rubles; $\mathrm{S}_{\mathrm{p}}$ is the average monthly salary per employee, rubles/person; SR is the salary return, rubles/rubles; $\mathrm{CC}$ is the capital coefficient of the enterprise, rubles/rubles; $\mathrm{PV}$ is the average monthly production volume, rubles; CL is a capital-labor ratio of the enterprise, rubles/person.

The authors propose the concept of a program for the development of a rational structure of employment in the labor market in the conditions of sustainable development of the Republic of Belarus, including the circular economy.

The first is the formation of a matrix of existing and potential jobs with technical and technological parameters, parameters of "green economy"and determination of the list of skills and abilities that should be provided at different timeswith different time delays of prospects in the national and cross-border labor market. This is possible through a comprehensive analysis of indicators reflecting the current situation in the labor market and policy documents of the countries.

The analysis of policy documents of the countries forming the cross-border labor market, characterizing trends in education, socio-economic development of national economies, employment regulation, development of "green" economy, analysis of the coefficients of complex intermediate import, export value will allow to make a matrix of potential jobs with technical and technological parameters and determine the platform of skills and abilities to meet different time delays of prospects.

The second is the creation of a web-based tool to match labor resources with the technological parameters of jobs in the cross-border countries: 
$\checkmark$ Identify potential jobs [22] and requirements for them in the"green" sectors of the economy

$\checkmark$ Constantly update the technical and technological parameters of jobs in accordance with the development of circular and "green" economy, as well as the global risks of society by sectors and industries

$\checkmark$ Align job requirements in the medium term with the requirements of the "human capital - physical capital - integrated algorithms" system

$\checkmark$ Monitor jobs that require the generation of ideas and creativity.

The synergistic effect of interaction "...lies in combining the efforts of natural and intellectual capitals of states and aligning the rates of international educational programs and infrastructure of economies. In this regard, the social effect for the target audience lies in wider involvement of the target audience in social processes taking place in the region and the state, reducing unemployment, increasing the level of income of the population, improving the social climate, increasing trust to the authorities and public organizations. The economic effect of interaction is to increase the contribution of this group of people to the most important indicators of regional and state development, primarily in the growth of the gross regional product"[22] It is also inclusive economic growth due to the inclusion of labor resources of older working age and older than the working age workforce, the synergistic educational effect of expanding the skills and abilities of states, efficient distribution of the workforce across the sectors of states through pendulum migration, the sharing of experience, and flexible forms of adaptation to educational programs.

The third is a revision of the mechanism of interaction between labor market actors. Implementation of the institutional model for achieving rational employment with the allocation of institutions that contribute to the collection of information on skills and abilities for the "green" economy will allow collecting information about jobs in the labor market with different projections of time lag, the workforce of different age, gender, and qualifications, as well as form a mechanism to adapt the structure of professional skills labor supply in a preventive manner for the emerging skills in the workplace taking into account the different rate and time of their emergence in the "green" economy.

\section{Conclusions}

Thus, we can conclude that the efficient use of resources in the field of energy efficiency based on the principles of circular economy, in this study is as follows: use fewer resources - use them more efficiently - you can maintain your competitive advantage - create green growth - create sustainable jobs - better protect the environment.

The conceptual principle within the framework of this study is the effective resource management in a circular economy to ensure the competitiveness of the region (on the example of the woodworking industry), which is to analyze the efficiency of the use of material resources and the use of production waste. The practical significance of the implementation lies in the possibility of tracking the chain of rational use of primary raw materials (in the woodworking industry) at all stages of the life cycle from the moment of planning the purchase of raw materials (primary or secondary raw), delivery, and to the recycling of the product. It is also an opportunity to bring an enterprise to low-waste or non-waste production, the possibility of recycling the products produced by this enterprise, along with economic (reduction of negative externalities and, accordingly, reduction of the amount of environmental tax) and environmental (reduction of negative externalities and, accordingly, reduction of environmental damage) benefits.

Energy efficiency, in general, can be described by the formula:

$$
E E=\frac{E_{1}}{Q_{2}}-\frac{E_{0}}{Q_{0}}
$$


where $E_{1}, E_{0}$ are the indicators of energy consumption in the reporting and base periods;

$\mathrm{Q}_{1}, \mathrm{Q}_{0}$ are the indicators of the result of the activity to which the energy consumption was directed.

Energy efficiency should be understood as the process of optimal use of energy resources, taking into account at least the economic, environmental, and social components in a certain period. Technologies and measures can become energy efficient and in such case they will ensure: the competitiveness of the economy; improvement of health, comfort, and safety of the people; improvement of productivity and efficiency of labor and production; reduction of environmental impact and depletion of natural resources; limitation of greenhouse gases emissions into the atmosphere; reduction in operating and maintenance costs; increase in the service life of units, components, and equipment; elimination of obsolete and surplus equipment; reduction of utility costs, etc.

The balance of employment in the labor market in a circular economy is a dynamic balance of the professional and qualification structure of labor supply and economically feasible jobs to ensure energy efficiency, including through resource conservation, the achievement and maintenance of which is possible with the management of sustainable economic development indicators that determine the demand and supply of labor resources at every moment of socio-economic, circular economic development[22], and the development of a mechanism for the coordination of both parties.

\section{References}

1. World experience in energy conservation. [Electronic resource]. - Access mode: https://www.iiec.org/ - Data mode: 09.04.2020.]

2. M.S.Smithet al.Advancing sustainability science for the SDGs, Sustainability science, 13(6), 1483-1487(2018).

3. The report of the Greenpeace organization - 2018 edition. [Electronic resource]. Access mode: https://www.greenpeace.org/international/explore/about/annual-report/ (date of application: 12.09.2019).

4. S.N. Popova, Economic content and principles of resource efficiency. Bulletin of Siberian science,5(6), 173-177(2012).

5. S.Huysman, S.Serenella, L.Mancini, F.Ardente, A.F. Rodrigo Alvarenga, Steven De Meester, F.Mathieux, Jo Dewulf. Toward a systematized framework for resource efficiency indicators, Resources, Conservation and Recycling,95, 68-76(2015).

6. J.Korhonen, A.Honkasalo, J.Seppala, Circular Economy: The Concept and its Limitations. Environmental Economics, 143, 37-46(2018)

7. Green Deal. Communication from the commission to the European parliament, the European council, the council, the European economic and social committee and the committee of the regions the European Green Deal com/2019/640 final. [Electronic resource]. - Access mode: https://eur-lex.europa.eu/legalcontent/EN/TXT/?qid=1596443911913\&uri=CELEX:52019DC0640\#document2 (date of application: 30.04.2020).

8. M. Skousen,The Big Three in Economics: Adam Smith, Karl Marx, and John Maynard Keynes. (ME Sharpe, 2007).

9. N. Batova, E.Shershunovich, I. Tochitskaya, The circular economy in Belarus: barriers to transition,BEROC Green Economy Policy Paper Series, 9, 1-20 (2019) 
10. N. Batova, P.Sachek, I. Tochitskaya,The circular economy in action: forms of organization and best practices, BEROC Green Economy Policy Paper Series, 5, 1-20 (2018)

11. N.V. Pakhomova,K.K. Richter,M.A. Vetrova, Transition to a circular economy and closed supply chains as a factor in sustainable development Bulletin of St. Petersburg State University. Economy, 33(2), 244-268 (2017).

12. G.B. Malyshkov,V. Viktorova, Economic methods of environmental protection: current situation and ways of modernization. Notes of the Mining Institute, 201, 71-78 (2013)

13. M. Geissdoerfer,P. Savaget,N. Bocken,E. Jan. Hultink, The Circular Economy - A new sustainability paradigm? Journal of Cleaner Production, 143: 757-768(2016).

14. Towards a Circular Economy: Business Rationale For An Accelerated Transition, (Ellen MacArthur Foundation, 2015).

15. F.Donati, G. A.Aguilar-Hernandez, C. P.Sigüenza-Sánchez, A.de Koning, J.F. Rodrigues, A. Tukker, Modeling the circular economy in environmentally extended input-output tables: Methods, software and case study. Resources, Conservation and Recycling, 152, 104508(2020).

16. H. Wilts Germany on the Road to a Circular Econmy? (Friedrich-Ebert-Stiftung, Division for Economic and Social Policy, 2016).

17. R.Bishop, Raising energy efficiency standards to the global best, (New Climate Economy, 2015).

18. H.Yaryhina,I.Ziankova,R.S. Sati, Global Energy Security, and International Economic Development. Bulletin of Kharkiv National University named after VN Karazin series "Economic", 98: 63-78,(2020)

19. Distributed power generation for Lebanon Market Assessment and Policy Pathways, May 2020 [Electronic resource]. - Access mode: http://documents1.worldbank.org/curated/en/353531589865018948/pdf/Distributed-

Power-Generation-for-Lebanon-Market-Assessment-and-Policy-Pathways.pdf (date of application: 25.04.2020).

20. Electricité de Zahlé (EDZ) [Electronic resource]. - Access mode: http://www.edz.com.lb/Systems_Technologies (date of application: 25.09.2020).

21. I.V. Zenkova, Mechanism of sustainable development of the aggregate labor market/ Journal: Bulletin of Polotsk state university. Series D. Economic and legal sciences, $\mathbf{6}$, 5-12(2013)

22. I.V. Zenkova, Some aspects of the conceptual framework for the development of a rational employment structure in the labor market: national and world experience/ consumer cooperation/Belarusian Republican Union of Consumer Societies Belkoopsoyuz),Belarusian Trade and Economic University of Consumer Cooperatives (Gomel),4(67), 17-25(2019) 